\title{
Penerapan Keselamatan Dan Kesehatan Kerja Pada Perawat \\ Di Rumah Sakit
}

Sophia Lumbanbatu

sophialumbanbatu@gmail.com

\section{Latar Belakang}

Rumah sakit merupakan salah satu tempat kerja yang memiliki tenaga kerja yang banyak dengan tingkat resiko yang tinggi terkena penyakit akibat kerja ataupun kecelakaan kerja.

Oleh karena itu rumah sakit waib untuk melakukan pencegahan yaitu dengan menerapkan

program kesehatan dan keselamatan kerja di rumah sakit. Kesehatan dan keselamatan kerja

merupakan salah satu bentuk nyata dalam menciptakan tempat kerja yang aman, lingkungan

yang sehat dan terbebas dari penyakit akibat kerja ataupun kecelakaan kerja. Metode: Jenis penelitian ini adalah penelitian kualitatif dengan jumlah informan penelitian berjumlah 7 (tujuh)

orang. Penelitian ini dilakukan pada bulan Mei sampai bulan Juli 2019. Hasil: Program K3RS

yang telah dilaksanakan adalah program pengembangan kebijakan K3RS, pembudayaan perilaku

K3RS, pengembangan SDM K3RS, pelayanan kesehatan kerja, pelayanan keselamatan kerja, 
pemantauan kesehatan lingkungan kerja, pengembangan pedoman, petunjuk teknis dan SOP,

pengembangan program pemeliharaan pengelolaan limbah padat, cair dan gas, pengelolaan jasa,

bahan beracun berbahaya dan barang berbahaya, pengumpulan data, pengolahan dan pelaporan

K3RS, review program tahunan, sedangkan yang belum maksimal dilaksanakan adalah program

pengembangan manajemen tanggap darurat. Kesimpulan: Pelaksanaan Program K3RS sudah

berjalan namun belum maksimal dilaksanakan. Saran: Rumah sakit perlu menambahkan sarana

prasarana tanggap darurat kebakaran seperti hydrant, alarm kebakaran, detektor asap dan alat

pemadam api ototmatis (sprinkler).

Kata Kunci : Kesehatan dan Keselamatan Kerja ,Rumah Sakit

Metode :

Jenis penelitian ini adalah penelitian kualitatif. Penelitian dilaksanakan di Rumah Sakit Tingkat II Robert Wolter Mongisidi Kota Manado pada bulan Mei sampai bulan Juli 2019. Informan dalam penelitian ini adalah Direktur Rumah Sakit atau wakil, ketua tim K3RS, kepala perawat, 1 (satu) perawat, 2 (dua) staf dan 1 (satu) cleaning service/petugas kebersihan. Instrumen penelitian dalam pelaksanaan penelitian ini adalah peneliti sendiri dengan tambahan instrumen berupa alat perekam suara. Metode pengumpulan data dilakukan dengan cara observasi, wawancara, dokumentasi, dan triangulasi.

Hasil : 
Penelitian yang di lakukan oleh Ardi dan Haryono (2018) tentang Analisa Penerapan Budaya Perilaku K3 di Rumah Sakit menunjukan bahwa, dengan adanya kebijakan terkait K3 di rumah sakit maka budaya K3 akan lebih baik. Dalam penelitian ini rumah sakit telah mengeluarkan kebijakan terkait K3 yaitu dengan Surat Keputusan yang telah dibuat. Dalam Surat Keputusan tersebut dibentuk tim kesehatan dan keselamatan kerja rumah sakit beserta dengan anggotanya. Namun, penelitian ini tidak sejalan dengan penelitian yang telah dilakukan oleh Ivana dkk (2014) tentang Analisa Komitmen Manajemen Rumah Sakit Terhadap Kesehatan dan Keselamatan Kerja pada Rumah Sakit Prima Medika Pemalang yang dalam hasil penelitiannya menunjukan RS Prima Pemalang sudah memiliki komitmen dan kebijakan rumah sakit tetapi belum diwujudkan secara tertulis.

Pembahasan

Era globalisasi merupakan salah satu tuntutan dari perkembangan zaman yang dimana berbagai persaingan bisnis menjadi semakin ketat dan kebutuhan manusia juga semakin meningkat, termasuk kebutuhan akan layanan kesehatan. RS Umum adalah RS yang memberikan pelayanan kesehatan pada semua bidang dan jenis penyakit.1 Pelayanan RS merupakan bagian yang tidak terpisah dari sistem pelayanan kesehatan pada umumnya.2 Dalam pemberian pelayanan kesehatan, RS diharapkan dapat memberikan pelayanan yang berkualitas.3 Potensi bahaya di RS dapat disebabkan oleh faktor biologi, faktor kimia, faktor ergonomi, faktor fisik, faktor psikososial, bahaya mekanik , bahaya listrik, limbah RS yang dapat mengancam jiwa dan kehidupan bagi para karyawan RS, pasien maupun para pengunjung yang ada dilingkungan RS yang 
mengakibatkan penyakit dan kecelakaan akibat kerja. 4,5 Kesehatan dan Keselamatan Kerja (K3) merupakan suatu upaya perlindungan kepada tenaga kerja dan orang lain yang memasuki tempat kerja terhadap bahaya dari akibat kecelakaan kerja.6 Tujuan K3 adalah mencegah, megurangi, bahkan menihilkan resiko penyakit dan kecelakaan akibat kerja (KAK) serta meningkatkan derajat kesehatan para pekerja sehingga produktivitas kerja meningkat.7 Dalam Undang-Undang Republik Indonesia Nomor 36 Tahun 2009 Tentang Kesehatan, upaya kesehatan kerja ditunjukkan untuk melindungi pekerja agar hidup sehat dan terbebas dari gangguan kesehatan serta pengaruh buruk yang diakibatkan oleh pekerjaan sehingga sudah seharusnya pihak pengelola RS menerapkan upaya-upaya K3 di RS.8 K3 termasuk sebagai salah satu standar pelayanan yang dinilai di dalam akreditasi RS, disamping standar pelayanan lainnya. Pekerja RS mempunyai risiko lebih tinggi dibanding pekerja industri lain untuk terjadinya Penyakit Akibat Kerja (PAK) dan KAK, sehingga perlu dibuat standar perlindungan bagi pekerja yang ada di RS.4 Untuk mencegah dan mengurangi resiko bahaya tersebut maka perlu ditetapkan standar K3 di RS. Perlunya pelaksanaan K3RS mengenai kebijakan pemerintah tentang RS di Indonesia adalah untuk meningkatkan akses, keterjangkauan, dan kualitas pelayanan kesehatan yang aman diRS. Perencanaan, pelaksanaan, monitoring, dan evaluasi K3 RS serta tindak lanjut, yang merujuk pada SK Menkes No. 432/ Menkes/ SK/ IV/ 2007 tentang Pedoman Manajemen K3 di RS dan OHSAS 18001 tentang Standar Sistem Manajemen K3. Sistem manajemen K3RS adalah bagian dari sistem manajemen RS.

Pelayanan Keselamatan Kerja Rumah sakit telah melaksanakan pengawasan yaitu dengan melakukan pemeriksaan terhadap fasilitas sarana prasarana yang dilakukan setiap bulan. Untuk pemeliharaan alat kesehatan dengan melakukan kalibrasi alat yang dilakukan setiap 1 (satu) tahun sekali. Pengawasan yang dilakukan sudah sesuai dengan Undang-undang Republik Indonesia No 44 Tahun 2009 pasal 16 ayat (2) yang menyatakan bahwa peralatan medis harus diuji dan juga dilakukan kalibrasi secara berkala. Pelaksanaan pembinaan dan pengawasan perlengkapan keselamatan kerja yang telah dilaksanakan pihak rumah sakit yaitu telah menyediakan APD berupa sarung tangan, masker, APAR lengkap dengan SOP penggunaan, adanya jalur evakuasi dan titik kumpul untuk keadaan darurat. 
Pemantauan dan Evaluasi Kesehatan Lingkungan Kerja Pelaksanaan pembinaan dan pengawasan lingkungan kerja telah dilakukan oleh pihak rumah sakit. Pelaksanaan tersebut meliputi pemeriksaan seluruh area kerja yang memiliki resiko bahaya fisik, kimia ataupun biologi. Pengawasan juga dilakukan disetiap area kerja yang beresiko seperti tanda perhatian yang diletakkan di area beresiko jatuh ataupun untuk lantai yang licin dilakukan pergantian dengan yang tidak licin. Selanjutnya dilakukan evaluasi untuk tindakan selanjutnya. Hal ini sesuai dengan Kemenkes RI No 1087 Tahun 2010 yang menyatakan bahwa tempat kerja harus menyedian dan menyiapkan lingkungan kerja yang memenuhi persyaratan baik fisik, kimia dan biologi melalui kegiatan pengawasan secara rutin kemudin melakukan evaluasi dan tindakan penanganan untuk perbaikan lingkungan kerja. Namun, penelitian ini berbanding terbalik dengan penelitian yang dilakukan oleh Tamboto (2017) tentang Analisis Penerapan Standar Pelayanan Kesehatan Kerja Di Rumah Sakit Gmim Kalooran Amurang Kabupaten Minahasa Selatan, dalam penelitiannya menunjukan bahwa rumah sakit belum melaksanakan pemantauan lingkungan kerja.

Pengembangan Pedoman, Petunjuk Teknis dan SOP Pengembangan pedoman K3RS telah dilakukan oleh rumah sakit yaitu dengan adanya pedoman pelaksanaan K3, pedoman pencegahan dan penanggulangan kebakaran dan penyusunan SOP kerja untuk masingmasing unit kerja. Di setiap ruangan telah tersedia alat keselamatan dan juga ada SOP untuk penggunaan serta SOP untuk keadaan tanggap darurat berupa prosedur pencegahan dan penanggulangan kebakaran. Penelitian ini sesuai dengan Peraturan Menteri Tenaga Kerja dan Transmigrasi Republik Indonesia Nomor 08 Tahun 2010 tentang alat pelindung diri yang menyatakan bahwa pimpinan suatu tempat kerja ataupun tenaga kerja yang telah lama bekerja wajib memberikan informasi secara tertulis dan memasang SOP untuk penggunaan APD di tempat kerja.

Faktor Penghambat Pelaksanaan Program K3RS Pelaksanaan program kesehatan dan keselamatan kerja di rumah sakit telah dilaksanakan dengan baik program K3RS sudah ada dan berjalan. Namun, ada beberapa kendala yang menghambat pelaksanaan program, yaitu karyawan baru yang belum diberikan sosialisasi terkait K3 dikarena jadwal yang padat sehingga belum sempat di berikan sosialisasi. Sosialisasi biasanya di 
lakukan ketika karyawan dinyatakan diterima bekerja telah bekerja kurang lebih 1 (satu) bulan setelah mereka bekerja. Rumah sakit tidak memiliki tenaga khusus ahli K3RS. Penelitian ini sejalan dengan penelitian yang di lakukan oleh Ristiono dan Azkha (2010), hasil penelitiannya menunjukan bahwa salah satu faktor penghambat pelaksanaan K3RS adalah sumber daya manusia.

\section{Penutup}

1. Bagi manajemen RS diharapkan membuat langkah awal menerapkan Sistem Manajemen Keselamatan dan Kesehatan Kerja yaitu menyatakan komitmen dan kebijakan tentang K3 secara tertulis.

2. RS diharapkan membuat struktur organisasi yang khusus menangani masalah K3RS agar tugas dari masing - masing unit lebih optimal.

3. RS diharapkan mengadakan sumber daya manusia untuk K3 baik itu merekruitmen karyawan baru maupun mengikutkan pelatihan K3 kepada karyawan yang sudah ditunjuk untuk menangani masalah K3RS. 4. Bagi peneliti perlu adanya penelitian lanjutan mengenai pembuatan P2K3 RS dan pembuatan perencanaan program K3RS.

\section{Daftar Pustaka}

1. Ferlina Maringka*, Paul A. T. Kawatu*, Maureen I. Punuh*,2019, ANALISIS PELAKSANAAN PROGRAM KESEHATAN DAN KESELAMATAN KERJA RUMAH 
SAKIT (K3RS) DI RUMAH SAKIT TINGKAT II ROBERT WOLTER MONGISIDI KOTA MANADO, Jurnal KESMAS, Vol. 8, No. 5, Juli 2019, Fakultas Kesehatan Masyarakat Universitas Sam Ratulangi Manado.

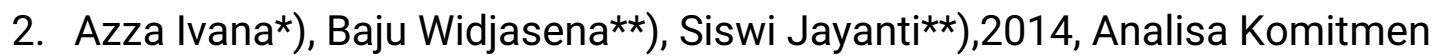
Manajemen Rumah Sakit (RS) Terhadap Keselamatan Dan Kesehatan Kerja (K3) Pada RS Prima Medika Pemalang, JURNAL KESEHATAN MASYARAKAT (eJournal), Volume 2, Nomor 1, Januari 2014,FKM UNDIP.

3. Simamora, R. H. (2011). ROLE CONFLICT OF NURSE RELATIONSHIP WITH PERFORMANCE IN THE EMERGENCY UNIT OF HOSPITALS RSD DR. SOEBANDI JEMBER. The Malaysian Journal of Nursing, 3(2), 23-32. 